\title{
Antioxidant and angiotensin converting enzyme (ACE) inhibitory activities of cocoa (Theobroma cacao L.) autolysates.
}

\begin{abstract}
The present study investigated antioxidant and angiotensin converting enzyme (ACE) inhibitory activities of cocoa autolysates. After removal of cocoa fat, alkaloids and polyphenols, the remaining proteinous powder was autolyzed at $\mathrm{pH} 3.5$ and 5.2. At similar concentrations, autolysates produced at $\mathrm{pH} 3.5$ indicated the highest reducing power and ACE inhibition activity. However, those generated at $\mathrm{pH} 5.2$ showed the highest antioxidant activity based on $\beta$-carotene bleaching assay. The results displayed a dose-dependent trend. Based on amino acids composition, slight differences were detected between autolysates, and as it was found, they were rich in hydrophobic amino acids. Qualitative and quantitative tests were applied to assure that the results from the assays were not due to the polyphenols of cocoa autolysates. Based on the results no polyphenols could be detected from cocoa autolysates. It can be indicated that among other useful substances of cocoa, its peptides and amino acids could contribute to its health-promoting properties. Furthermore, these bioactive substances can be exploited into functional foods or used as a source of nutraceuticals.
\end{abstract}

Keyword: ACE inhibition; Antioxidant activity; Autolysate; Cocoa (Theobroma cacao L.) 